\title{
MATERNIDAD Y TRANSGRESIONES PENALES EN EL DISTRITO FEDERAL, 1940-19501
}

\author{
Martha Santillán Esqueda \\ Universidad Nacional Autónoma de México
}

n junio de 1950 la estadounidense Vera Hunt, hija de un
millonario comerciante, vacacionaba en la ciudad de Méxi-
co y protagonizó el infanticidio que mayormente capturó la
atención de la prensa de la época. La recamarera que aseaba
la habitación de los Hunt en el "lujoso" Hotel del Prado descu-
brió en el bote de basura un bebé muerto con una gasa alrededor
del cuello. Tres días más tarde, el juez de instrucción dejó a la
estadounidense en libertad sirviéndose del examen de los médi-
cos legistas quienes, según sus investigaciones, el niño nunca res-

Fecha de recepción: 3 de agosto de 2017

Fecha de aceptación: 11 de mayo de 2018

\footnotetext{
1 Agradezco a Valeria Pita (Universidad de Buenos Aires) y a Florencia Gutiérrez (Universidad Nacional de Tucumán) las lecturas de borradores preliminares, así como a los dictaminadores anónimos por sus observaciones y sugerencias. A Alberto Romero agradezco su apoyo en las labores de corrección de texto y de elaboración de formato.

2 "Nuevas revelaciones en el escandaloso caso de Vera Hunt", La Prensa (18 jun. 1950), p. 38.
} 
piró fuera del seno materno. ${ }^{3}$ Para el diario La Prensa resultaba “asqueante la corrupción de nuestra justicia”. ${ }^{4}$ La resolución generó una profunda indignación entre los redactores del rotativo, quienes durante los siguientes días se ocuparon de cuestionar los procedimientos judiciales, de encarar al juez de instrucción y al ministerio público, así como de entrevistar a diversos especialistas. Los diputados y abogados Milton Castellanos y David Franco, al ser consultados sobre el caso, aseguraron que "por fortuna, en nuestro país delitos de esa naturaleza son poco comunes y van contrariamente a los sentimientos maternales de las mujeres mexicanas". ${ }^{5}$

Para los años cuarenta, los sentimientos maternos de las mexicanas se habían convertido abiertamente en un tema de gran preocupación, tanto política y social como científica y mediática. En ese sentido, las transgresiones penales que atentaban contra el ideal materno evidenciaban tensiones propias del momento tales como la modernización urbana y su vínculo con las nuevas posibilidades de desarrollo personal ofrecidas para las mujeres tras la gesta revolucionaria. Conjuntamente con la llegada al gobierno de Manuel Ávila Camacho (19401946), comenzó en México una época de bonanza económica y de estabilidad social, que en los ámbitos de la educación y la moral posibilitaron retomar el curso del conservadurismo; ${ }^{6}$ esto es, una búsqueda por defender esquemas morales tales como la familia patriarcal, ciertamente heredado del siglo anterior pero que para estos años redefinía sus usos políticos y sociales. ${ }^{7}$ En

3 "El certificado médico dice...", El Universal (17 jun. 1950), 2a sección, pp. 1,12 .

4 “El juez se justifica y acusa al Ministerio Público...”, La Prensa (21 jun. 1950), p. 35. Analizamos otra faceta del caso en el capítulo VI, p. 330.

5 "El delito de infanticidio está confuso en el código", La Prensa (21 jun. 1950), pp. 2, 26.

6 SAntillán Esqueda, "Discursos de redomesticación”.

7 Muñız, Cuerpo, representación. Para concepciones de la época respecto al ideal de familia véase BERMÚDEZ, La vida familiar. 
este contexto, el ser madre reivindicaba "la importancia de las mujeres en la sociedad" en tanto que se convertía en un asunto público regulado por el Estado. ${ }^{8}$

En particular desde la década de los treinta había comenzado a implementarse una serie de servicios de apoyo y protección a la maternidad, ${ }^{9}$ al tiempo que se diseñaban campañas políticas o mediáticas de veneración a las madres para instruir a las mexicanas en su importante tarea materna, y que a la vez fortalecían el binomio madre-hijo. ${ }^{10}$ Ello se refleja claramente en la imagen de la madre abnegada y amorosa, la cual también era ampliamente difundida por el cine y la prensa. ${ }^{11}$ Estereotipo a su vez concordante con el esquema de maternidad promovido por la doctrina católica, que circunscribía las conductas femeninas sexuales y amorosas a su familia, esposo e hijos, ${ }^{12}$ y que para estos años presentaba a la Virgen María como el modelo perfecto de mujer. ${ }^{13}$

Por su parte, los especialistas de la época se asumían autorizados para orientar "científicamente" a padres y madres en

8 Lau Jaiven, "Mujeres, feminismo", p. 71.

9 Muestra de ello es el programa La Gota de Leche, que tenía como finalidad distribuir alimento a los niños mal nutridos, así como difundir medidas de higiene y nutrición; véase VIESCA, “La Gota de Leche”. También las prerrogativas otorgadas a las madres trabajadoras en la Ley Federal del Trabajo (1931), y los servicios ofrecidos por el Seguro Social (1943) a las mujeres trabajadoras; véase SANTILlán Esqueda, “Mujeres y leyes”, pp. 133-135; Cruz Salinas, “Mathilde Rodríguez Cabo".

10 A la par de la maternidad, la infancia cobraba gran relevancia política para especialistas y autoridades. Para profundizar al respecto véase PADILLA, "Infancia en vilo"; SosENSKI, El trabajo infantil.

11 Para más detalle sobre la construcción del ideal materno a través del cine véase TuÑón, Mujeres de luz; y en la prensa, SANTILlán EsQueda, “El discurso tradicionalista”, pp. 90-110.

12 MuñIz, Cuerpo, representación, p. 75.

13 El papa Pío XII declaró en noviembre de 1950 el dogma de la asunción de la Virgen María, y le dedicó el año de 1954. Las familias católicas del periodo de estudio festejaban esta figura a lo largo del mes de mayo. Torres SEPTiÉn, "Una familia de tantas", pp. 199-202. 
la procreación de sus hijos: "el médico [...] es el único responsable de la compleja obra social, educativa y médico-higiénica que ha de conducir a la creación de nuevas formas de vida para madres y niños", y con ello la existencia de mejores ciudadanos, aseguraba la médica y feminista Matilde Rodríguez Cabo. ${ }^{14}$ Sin embargo, tal como sostiene Beatriz Urías, aquellos esfuerzos institucionales a la vez circunscribieron "la sexualidad femenina al matrimonio y, dentro de éste, a la función reproductora”. ${ }^{15}$

Aquellas visiones pretendían afianzar la existencia de la familia patriarcal, la cual se suponía atacada por la modernización, que propiciaba la modificación de las conductas femeninas resultado de una serie de cambios sociales y jurídicos. ${ }^{16} \mathrm{El}$ nuevo marco jurídico posrevolucionario resultó ser más equitativo para las mexicanas al posibilitarles mayores oportunidades de desarrollo fuera del hogar en los ámbitos educativos, culturales y laborales. ${ }^{17}$ Así, pues, las élites en el poder temían que la incorporación de las mujeres en la esfera pública pudiera provocar en ellas el desprecio de las obligaciones domésticas, el rechazo a la maternidad y el relajamiento de la moral, lo cual se consideraba

\footnotetext{
14 AH-UAER-UNAM-J, $M R C$, c. 1, carp. 15, doc. 5, p. 3, “Asistencia maternal”, texto mecanografiado (s/f). Matilde Rodríguez Cabo fue la primera médica psiquiatra en México y una destacada líder feminista que participó en el movimiento por la protección a la infancia y en la lucha por los derechos políticos, sociales y humanos de las mujeres, al tiempo que mostró preocupaciones por temas relacionados con la delincuencia y los comportamientos antisociales de procesados y alienados. Fue directora del pabellón infantil en el Manicomio General La Castañeda (1931) y estuvo al frente del Consejo Supremo de Defensa y Previsión Social (1930). Formó parte del Frente Único Pro Derechos de la Mujer (creado en 1935). Las opiniones de Rodríguez Cabo respecto a la maternidad en el periodo estudiado son relevantes en tanto que muestran visiones de especialistas más críticas y propositivas. Véase CANO, "Una perspectiva"; SOSENSKI y SOSENSKI, "En defensa”.

15 Urías Horcasitas, "Eugenesia y aborto", p. 309.

${ }_{16}$ MuñIz, Cuerpo, representación; SANTILlán Esqueda, "Posrevolución y participación”.

17 Véase Santillán Esqueda, "Mujeres y leyes".
} 
degradante no solo para las mujeres, sino también para la familia $y$, en consecuencia, para la sociedad en su conjunto.

Cabe destacar que en aquel ambiente de políticas públicas y cambios sociales, en el derecho penal no se verificaron cambios sustanciales. En el código posrevolucionario de 1931 la tipificación y los castigos de los delitos asociados con la maternidad (aborto, infanticidio, abandono y robo de infante) se mantuvieron con penas bajas y prácticamente iguales que en los ordenamientos precedentes de 1929 y $1871 . .^{18}$ Así, mientras en lo penal existían consideraciones con las delincuentes de este tipo, en lo discursivo se evidenciaba una exacerbación de las visiones respecto a las transgresiones relacionadas con el ideal materno.

La historiografía del crimen que mira hacia la comprensión de las prácticas delictivas femeninas generalmente ha encontrado en el aborto y el infanticidio un terreno rico de análisis por su evidente relación con la maternidad. Asimismo, se ha logrado demostrar la existencia de diferenciaciones de género en el derecho y, por ende, en la administración de la justicia penal, que han caracterizado a estos delitos como típicamente femeninos. ${ }^{19}$ Por otro lado, el tema se ha estudiado principalmente hacia finales del porfiriato y principios del siglo $\mathrm{xx}$, analizando en particular los discursos de género contenidos en las miradas y visiones de especialistas, médicos y juristas, ${ }^{20}$ aunque también se ha buscado comprender tales normativas como mecanismos de control que buscan restringir la acción femenina a una experiencia materna

18 A lo largo de este trabajo se harán las menciones pertinentes al código penal de 1931. Para más detalle respecto a los ordenamientos anteriores, véase SANTILLÁn EsquedA, "Mujeres y leyes”.

19 Birgin, El género; Santillán Esqueda, "Mujeres y leyes”; Smart, "La teoría feministas"; Speckman Guerra, "Las flores del mal”;

20 Para el siglo xix: NúÑez Becerra, "De una práctica privada”; Rodríguez RAYGOZA, “¿Víctimas o victimarias?”. Para las primeras tres décadas del siglo xx, Urías Horcasitas, "Eugenesia y aborto”; Núñez Cetina, "Reforma social". 
específica. ${ }^{21}$ En este sentido, el estudio de la honra femenina en el marco del derecho en relación con las visiones sociales ha sido otra preocupación historiográfica, en tanto que se ha buscado dar cuenta de mecanismos legales y discursivos que buscaron restringir la sexualidad femenina a la procreación en el marco conyugal. ${ }^{22}$ Igualmente, se ha analizado la experiencia delictiva para tratar de comprender los entornos sociales de las mujeres y su situación ante la existencia de embarazos e hijos no deseados. ${ }^{23}$ Ahora bien, son escasos los trabajos que se ocupan en comprender el fenómeno en el periodo propuesto en este artículo, ${ }^{24}$ y que a la vez busquen entender la complejidad del tema engarzándolo con el análisis de otras prácticas delictivas relacionadas con la experiencia materna, tales como el abandono y el robo de infante.

Para los años cuarenta los crímenes vinculados a la maternidad encuentran su especificidad en los esfuerzos de las autoridades por alentar una maternidad amorosa y comprometida con la crianza de hijos sanos física y mentalmente, las visiones de especialistas que procuraban incidir en la implementación de políticas públicas, así como el énfasis constante en medios como la prensa sobre el ideal materno. En este orden de preocupaciones, a partir del estudio de procesos judiciales por aborto, infanticidio, abandono y robo de infante, ${ }^{25}$ casos en prensa (en los diarios Excelsior, El Universal y La Prensa) y artículos

${ }^{21}$ Speckman guerra, "Morir en manos".

22 Speckman guerra, Elisa, "Las flores del mal”; Núñez Cetina, "Reforma social".

${ }^{23}$ NúÑez Becerra, "De una práctica privada”; Rodríguez Raygoza, “¿Víctimas o victimarias?".

${ }^{24}$ NúÑ̃z Cetina, "Reforma social”, enfoca el análisis entre 1920 y 1940; Santillán Esqueda, "Infanticidas en la ciudad”; Santillán Esqueda, Delincuencia femenina.

${ }^{25}$ Se cuenta con 19 procesos judiciales por aborto (en éstos hay 28 inculpadas: 16 madres, 8 parteras, 4 cómplices de las madres), 10 por infanticidio, 2 por abandono de infante y 9 por robo de infante (con 11 acusadas). 
especializados de la época, analizo los patrones sociales y discursivos que enmarcan estas prácticas delictivas. Me interesa, a partir de ello, caracterizar a las mujeres que encontraban en el delito una posibilidad para dirimir situaciones conflictivas tanto sociales como de índole económica en torno a ser madre, ya sea por transgredir el ideal materno como para ajustarse a él. Me ocuparé en las dos primeras secciones de las acciones criminales que atentaban contra el ideal materno (aborto, infanticidio, abandono de infante) y en la última de aquellas prácticas delictivas relacionadas con el robo de infante por medio de las cuales las mujeres buscaban ser madres.

\section{MATERNIDAD Y SEXUALIDAD VERGONZANTE:}

ABORTO E INFANTICIDIO

La Prensa reseñó el 1o de junio de 1949 que a lo largo y ancho de la ciudad de México fueron encontrados seis bebés muertos: un cadáver tirado en plena calle, otro en estado de putrefacción, otros dos con las piernas y los brazos devorados por animales, $\mathrm{y}$ unos mellizos metidos en una caja de zapatos. ${ }^{26}$ Aunque en la nota se aseguraba que las "desnaturalizadas madres" serían buscadas por la policía, la realidad es que las autoridades no tenían pista alguna sobre su identidad. Ciertamente, al igual que en épocas anteriores, en el periodo de estudio había mujeres que recurrían al aborto, al infanticidio o al abandono para resolver el problema que les representaba el embarazo o el nacimiento de un hijo, y solían deshacerse de los restos del feto o del bebé asesinado arrojándolos a basureros, barrancas, pozos, desagües, o abandonándolos con vida en sitios públicos que iban desde calles y plazas hasta hoteles e iglesias. Sin embargo, para los años cuarenta la alarma mostrada por la prensa evidencia una

26 "Quedaron al descubierto 6 abominables infanticidios", La Prensa (1 jun. 1949), pp. 12-13. 
preocupación ligada a los tiempos de cambio que se experimentaban en el país y que generaban ansiedad a los espíritus conservadores de la época.

Pocas voces, como la de la médica Rodríguez Cabo, insistían en la necesidad de educar mejor sexualmente a las jovencitas y promover el uso de métodos anticonceptivos, ${ }^{27}$ lo cual evitaría a la postre hijos maltratados o asesinados, mal alimentados, mal educados o sencillamente abandonados. ${ }^{28}$

Penalmente la diferencia entre el delito de abandono de infante y el aborto e infanticidio es que estos últimos eran un franco atentado contra la vida o la gestación de una vida, pero también se relacionaban penalmente con la necesidad de ocultar una deshonra sexual. El aborto era "la muerte del producto de la concepción" durante la preñez y la interrupción de una vida en gestación. La menor pena para el aborto oscilaba entre seis meses y un año de prisión, y se aplicaba a mujeres que no tenían mala fama y habían ocultado el embarazo resultado de una unión ilegítima; en otras circunstancias, se les podía adjudicar de uno a cinco años de cárcel. Cabe destacar que el embarazo podía interrumpirse cuando la mujer corría riesgos de salud o había sufrido una violación. ${ }^{29} \mathrm{El}$ infanticidio se sancionaba con seis a diez años de prisión cuando el padre o la madre causaba la muerte "a un niño dentro de las 72 horas de su nacimiento". Sin embargo, a las madres infanticidas sin mala fama y que habían ocultado un embarazo ilegítimo ante la sociedad y el Registro Civil, se les aplicaba una pena menor: de tres a cinco años de cárcel. ${ }^{30}$

${ }^{27}$ AH-UAER-UNAM-J, $M R C$, c. 1, carp. 15, doc. 2, "El problema sexual de las menores mujeres y su repercusión en la delincuencia juvenil femenina", texto mecanografiado $(\mathrm{s} / \mathrm{f})$.

28 Rodríguez Cabo, "El control”, p. 208.

${ }^{29}$ Código penal 1931, arts. 329-333.

30 Código penal 1931, arts. 325-327. 
Como puede observarse, en ambos casos, además de proteger la vida de los seres humanos por nacer o de los recién nacidos, había una clara y preponderante preocupación por la honra femenina y la familia. Por ello, se castigaba con mayor rigor a las mujeres sin honra o a quienes acababan con la gestación o la vida de un hijo legítimo. Ahora bien, puesto que no implicaba lo mismo interrumpir un embarazo que matar a un recién nacido (lo que se evidencia en la gradación de las sanciones), es importante hacer unas precisiones tanto penales como sociales, que más adelante se tomarán en cuenta para el delito de abandono de infante.

En principio el infanticidio era más penado en tanto que se mataba a un ser ya nacido. No obstante, penalmente era, en palabras del jurista Mariano Jiménez Huerta, una entidad desapegada del homicidio caracterizada por la benignidad de la sanción en función de la necesidad de ocultar el parto de un embarazo vergonzante y evitar el subsecuente deshonor propio y familiar, para lo cual se debía "sacrificar" al hijo. En tal sentido, si transcurrían más de 72 horas y se demostraba, continuaba el jurista, que la mujer no tenía urgencia por ocultar el nacimiento y, por tanto, el hecho criminal debía tratarse como un homicidio. ${ }^{31}$ De este modo, respecto al abandono de un hijo, se consideraba que la madre no tenía necesidad de ocultar el nacimiento por lo que no se consideraba la deshonra como atenuante.

En este sentido estricto, tanto para el aborto como para el infanticidio los jueces debían tomar en cuenta la "desesperación" de una mujer que ve en el crimen su única salida antes que reconocerse madres del producto de una relación ilegítima. Podemos entonces considerar que, aun cuando el acto criminal no sea el mismo, hay un punto en que ambas prácticas bien podían llegar a ser utilizadas para el mismo fin: rechazar la gestación o al hijo al nacer; esto es, rehusarse a ejercer la maternidad. De ahí que

31 Jiménez huerta, “Delito de infanticidio”, pp. 106 y 115. 
criminólogos y voces de la prensa llegaran a considerar que estos delitos eran consecuencia de conductas sexuales inapropiadas alentadas por la modernización que, supuestamente, llevaba a las mujeres a renegar de la obligación materna.

A pesar de la carencia de cifras oficiales, en el tránsito del siglo xIx al xx los hallazgos muestran un aumento paulatino en el número de procesos judiciales por aborto y una disminución en los de infanticidio. Elisa Speckman ha dado cuenta de la falta de procesos penales por aborto durante el porfiriato, aunque los registros oficiales indican que entre 1891 y 1898 hubo 79 consignadas por aborto y 165 por infanticidio; entre 1901 y 1910 fueron 109 y 52, respectivamente. En tanto, Elizabeth Rodríguez localizó para Jalisco, entre 1865 y 1873, 11 causas por aborto y 43 por infanticidio; sin embargo, ninguna de las 11 mujeres consignadas por aborto fue procesada, ya que se demostró en cinco casos que el aborto había sido involuntario o no hubo pruebas suficientes para continuar con el proceso en otros seis. Para la década de 1930, Saydi Núñez localizó seis procesos por aborto y 13 por infanticidio; en tanto, para el presente trabajo se cuenta con 16 y 10 , respectivamente. ${ }^{32}$

Estas tendencias delictivas son resultado de una serie de factores entre los que cuenta de manera importante el hecho de que las mujeres ya no solo ingerían tés y bebedizos diversos para interrumpir la gestación puesto que, como lo muestran las fuentes, las técnicas médicas y los instrumentos para abortar habían mejorado y estaban mucho más extendidos que antes. Además, había más parteras -instruidas o no- que ofrecían estos servicios de manera clandestina, generalmente en condiciones deplorables de higiene, pero a costos accesibles, y también médicos. Las intervenciones corporales consistían

\footnotetext{
32 Speckman Guerra, "Las flores del mal”, pp. 189, 228-229; Speckman, “Morir en manos", p. 318; Rodríguez Raygoza, “¿Víctimas o victimarias?, pp. 85-88; NúÑEz Cetina, "Reforma social”, p. 90.
} 
en la inserción de diversos artefactos en la vagina para picar al embrión o feto, provocar sangrado, contracciones y el subsecuente desprendimiento.

Por ejemplo, Clotilde Vence, una lavandera con "experiencia en partos”, colocó a Josefa Ocaña una sonda, parecida a una "tripa delgada de hule", que consiguió en la Plaza de Tacuba; posteriormente, le recomendó tomar una dosis de quinina en nueve cápsulas, tres pastillas Pelletiér para el dolor y otras sustancias desconocidas. ${ }^{33}$ La comadrona cobró por sus servicios 25 pesos que Josefa pagó con un reloj de bolsillo y 10 pesos en efectivo. El aborto fue exitoso. Sin embargo, días más tarde Josefa regresó con la partera a causa de fuertes dolores que ningún remedio conseguía eliminar; finalmente, fue a la Cruz Verde, donde se le realizó un legrado pues presentaba restos placentarios por aborto incompleto y fue denunciada a las autoridades. ${ }^{34}$ Fueron denunciados $50 \%$ de los abortos por autoridades médicas que atendían a las mujeres por complicaciones posaborto y que en ocasiones alcanzaban la muerte, en las que estaban implicadas parteras legas o tituladas. ${ }^{35} \mathrm{El}$ hecho de que entre las procesadas no hubiese mujeres de sectores sociales mejor avenidos se explica en tanto que tenían más recursos para asistir con médicos que ofrecían mejores condiciones de higiene pero a mayor costo.

Los servicios de comadronas para interrumpir un embarazo eran hasta cierto punto accesibles para mujeres de sectores populares, como Josefa. De acuerdo con las fuentes, a diferencia de los elevados honorarios médicos, los de las parteras oscilaban

33 AGN, TSJDF, AH-1, c. 3943, fol. 692108, Clotilde Vences González y Josefa Ocaña Salcedo, aborto (22 octubre 1947), fs. 2v.-4.

${ }_{34}$ AGN, TSJDF, AH-1, c. 3943, fol. 692108, Clotilde Vences González y Josefa Ocaña Salcedo, aborto (22 octubre 1947), fs. 2v. y 41.

35 De los 16 procesos penales por aborto, $37.5 \%$ fueron acusadas por personas conocidas (patrones, vecinos, conocidos); solo dos (12.5\%) inculpadas fueron atrapadas por la policía en una redada judicial a un consultorio médico. 
entre 12 y 50 pesos. ${ }^{36}$ Bertha Noriega aseguró haberle pagado a Eustolia Fernández 50 pesos por un aborto. Cuatro meses más tarde enfermó de "pelviperitonitis con piosalpinx [sic] izquierdo post-abortum”, y el médico Héctor Medellín Ostos cotizó la operación y el tratamiento en 400 pesos; por falta de recursos acudió al Hospital Juárez, donde fue denunciada a las autoridades. ${ }^{37}$

Practicarse un legrado exigía, pues, recursos materiales y redes sociales. En general, las madres acusadas de aborto tenían una situación económica, social y personal menos desfavorable que las infanticidas. El $25 \%$ de las abortadoras pertenecían a la clase media, el resto a sectores populares, ${ }^{38}$ en tanto que las infanticidas eran todas de sectores bajos. La diferencia en el perfil socioeconómico de las procesadas va de la mano con los motivos expresados para proceder a abortar o a matar a un recién nacido. Estas últimas en su mayoría eran originarias de provincia, analfabetas, solteras, se encontraban solas en la ciudad, se dedicaban al servicio doméstico y habitaban en el domicilio de sus patrones. ${ }^{39}$ Existían circunstancias importantes en torno al infanticidio: la marginalidad social, legal y económica en la que vivían la mayoría de las victimarias. Por un lado, eran mujeres

36 El salario mínimo diario en 1946-1947 era de 2.48 pesos, y para 1948 de 3.01 pesos. 50 años de Revolución Mexicana en cifras, México, Presidencia de la República, Nafinsa, 1963, p. 112.

37 AGN, TSJDF, $A H-2$, c. 437, exp. 18, Bertha Noriega Estrada, Eustolia Fernández y Rogelio Molina, aborto y lesiones (7 abril 1945), fs.1v., 7-9.

${ }^{38}$ El 62.5\% habían tenido algún grado de instrucción; solo $37.5 \%$ eran solteras, $56.25 \%$ tenían una relación de pareja, y una era viuda. En cuanto a su oficio, nueve $(56.25 \%)$ dijeron dedicarse al hogar y siete eran trabajadoras $(43.75 \%)$, de éstas, cuatro eran empleadas particulares, dos domésticas, una galopina y una obrera.

39 De los 10 procesos por infanticidio con los que contamos, todas pertenecían a la clase baja, $90 \%$ eran analfabetas y $70 \%$ se declararon solteras. El $80 \%$ se dedicaban al servicio doméstico, una era obrera y otra era ama de casa. El 80\% eran originarias de provincia, una era del Distrito Federal y otra no especificó su lugar de procedencia. 
solas y separadas de sus redes familiares y sociales, prestaban sus servicios sin protección laboral jurídica, estaban expuestas a abusos sexuales de sus patrones y, siguiendo la reflexión de Rodríguez Cabo, muy probablemente desconocían los procesos sexuales de sus cuerpos y de gestación; ${ }^{40}$ de ahí, quizá, que varias se dijeran sorprendidas por el parto.

Margarita Rodríguez trabajaba de recamarera en la colonia Roma; llegó a la capital a los 19 años, era soltera, analfabeta y tenía una hija de dos años. Se le vinculó, tras una llamada telefónica anónima a la policía, con el cadáver de un recién nacido encontrado en un basurero ubicado en las calles Medellín y Colima. El agente policial reportó que al ser detenida afirmó haber matado a su hijo para "cubrir su falta y la de su patrón, el señor José Rivera, padre del niño estrangulado, con quien tuvo intimidades y de quien recibía frecuentes donativos en dinero y temiendo que la esposa se diera cuenta, optó por desaparecer el fruto de sus amores". Después, ante el ministerio público, dijo que "tenía relaciones de concubinato con el señor Margarito García, del que ignoraba su domicilio”, y como no tenía recursos suficientes ni familia que le ayudase a mantener a esta segunda criatura, sumado a que con hijos se le dificultaba obtener empleo, decidió ahorcarla al nacer y depositar el cadáver en un basurero. ${ }^{41}$

Las "criadas" pertenecían a los sectores marginales capitalinos, conformados generalmente por indígenas analfabetas que migraban de provincia en busca de empleo y que lo encontraban en los hogares de la pujante clase media que se caracterizaba por sus “pretensiones burguesas”, comenta José Agustín. Estas

40 Rodríguez CAво, “El problema sexual”. En Jalisco, a mediados del siglo XIx, había este mismo desconocimiento de su cuerpo de varias victimarias, sobre todo si eran madres primerizas. Rodríguez RAygoza, “¿Víctimas o victimarias?".

41 AGN, TSJDF, AH-1, c. 357, fol. 643925, fs. 16 y 12v., Margarita Rodríguez Martínez, infanticidio (10 de septiembre de 1944). 
mujeres tenían que enfrentar los “asedios de los 'cazagatas' que pretendían llevárselas [...] a los colchones de los hoteles de paso (si es que el hijo del patrón, o el patrón mismo, no las habían asaltado ya en el más conveniente pero igualmente sórdido 'cuarto de servicio'...)". ${ }^{42}$ Esta situación parece que era bien sabida. El Universal señalaba que entre las clientas de la célebre partera apodada "La descuartizadora de la Roma”, se encontraban "criadas que habían sufrido deslices con sus mismos patrones, quienes se apresuraban a pagar 'para que todo quedara en tal estado"”. ${ }^{43}$ El criminólogo Félix Pichardo afirmaba, sin tomar en cuenta la situación de vulnerabilidad social y legal en que vivían las fámulas, que su "cercanía con los niños del 'patrón', en momentos en que se encuentra[n] a solas con ellos, [se] le[s] facilita desahogar sus equívocos apetitos sexuales, llegando a veces a su perversión". ${ }^{44}$

Como se ha mencionado, el aborto era una práctica más socorrida que el infanticidio. La interrupción de la gestación, aunque implicaba un mayor peligro para la salud y requería asistencia y dispendio, era un delito menos penado. En contraparte, el infanticidio exigía sólo tener la posibilidad de ocultar el embarazo y el parto, asesinar al neonato y deshacerse del cuerpo. Este crimen era un "delito solitario", como

${ }^{42}$ José Agustín, La tragicomedia, pp. 131-133. Diversas obras literarias de la época han retratado de manera incisiva las formas de vida familiar y cotidiana de la clase media capitalina a mediados de siglo. Algunas novelas relevantes: Azuela, "La nueva burguesía"; Spota, Casi el paraíso; Fuentes, La región y Pacheco, Batallas. En contraparte, para tener una visión sobre la realidad de la gente del campo, que era la que migraba a las ciudades, son reveladoras las obras de Rulfo, El llano en llamas y Pedro Páramo.

43 “Todo un grave problema social”, El Universal (19 abr. 1941), $2^{\mathrm{a}}$ sección, pp. 1, 10. La partera Felícitas Sánchez Aguillón fue acusada por los vecinos de practicar abortos; la prensa le imputó una serie de hallazgos de restos de fetos y recién nacidos, tanto en los desagües de la vivienda donde ella habitaba como en los alrededores, realizados en días anteriores a la detención. Este caso se estudia de manera detallada en SANTILlán Esqueda, "La Descuartizadora". ${ }^{44}$ Pichardo Estrada, "Criminología”, p. 173. 
lo denomina Elisa Speckman, en la experiencia del siglo xix: "podríamos pensar que las mujeres recurrían al infanticidio cuando no se atrevían a confesar su estado o no contaban con las redes de apoyo requeridas, pues el aborto involucraba varios actores mientras que el infanticidio era un acto individual". 45

Las procesadas generalmente se encontraban solas en la ciudad, buscaban proteger sus empleos y no contaban con los recursos económicos y las redes sociales necesarias para sostener al recién nacido o incluso para practicarse un aborto. Así sucedió con María Concepción Roque, quien llegó a la capital para trabajar como sirvienta. Cuando nació su hijo lo azotó en el piso y luego lo ahorcó porque se seguía moviendo; ya muerto, lo envolvió en trapos. Manifestó a La Prensa: "yo no quería al hijo [...] porque sería un obstáculo en mi trabajo. Por eso decidí matarlo [...] metí el cadáver en una red de ixtle y lo escondí bajo la cama. Esperaba una oportunidad para llevarlo a enterrar a mi tierra". ${ }^{46}$

Respecto a las motivaciones expresadas por las infanticidas, $50 \%$ aseguró haber matado a su recién nacido por cuestiones económicas, $20 \%$ por honra o amores ilícitos y otro $20 \%$ dijeron que el bebé había nacido muerto. En cambio, $18.75 \%$ de las procesadas por aborto afirmaron haberlo hecho por cuestiones económicas, $25 \%$ para ocultar una deshonra, $12 \%$ no querían tener al hijo, el resto por accidente, por salud, disgustos maritales o no decían.

Vinculado al peso de la carga económica, las acusadas tanto de aborto como de infanticidio alegaban ser víctimas del engaño, maltrato o abandono de los progenitores, generalmente concubinos "desconocidos" o amantes pasajeros que no se responsabilizaban pecuniariamente de sus hijos. Así sucedió

45 Speckman Guerra, “Las flores del mal”, pp. 189-190.

46 "Infame sirvienta ahorcó a su hijo recién nacido", La Prensa (28 oct. 1954), p. 25. 
con Eva González, originaria de Veracruz, soltera, que sabía leer y escribir, de 19 años y que trabajaba como sirvienta en la colonia Narvarte. La patrona encontró en el cuarto de servicio un vitrolero con alcohol que contenía un feto de aproximadamente cuatro meses de gestación. Eva declaró que tenía otra hija de cinco años de edad con Alberto Iniesta, quien no le cumplía las promesas de matrimonio ni le daba dinero para sostener a la niña. Al saberse nuevamente embarazada y sabiendo que su hija "sufrió mucho pues había días que no tenía un pan para alimentarla [...] y temiendo volver a sufrir con el nuevo ser”, decidió, sin consejo y sin ayuda de nadie, colocarse una sonda para abortar. ${ }^{47}$

Si bien la investigación de paternidad fue promovida desde 1917 con la Ley de Relaciones Familiares, y recuperada en el Código Civil de 1932, no era una herramienta legal muy socorrida. Las mujeres que alegaban haber sido enamoradas o seducidas (así fuera con promesas de matrimonio) ${ }^{48}$ no contaban con los mecanismos legales suficientes para obligar a un hombre a responsabilizarse del hijo. La investigación de la paternidad solo podía realizarse en caso de estupro, rapto o violación; cuando el hijo estuviese en posesión del padre; cuando los padres hubiesen habitado bajo el mismo techo maritalmente durante la concepción; o cuando el hijo tuviese pruebas contra el padre. ${ }^{49}$ Con todo, varias abortadoras o infanticidas alegaban haber sido "burladas”, “abandonadas”, “obligadas”, “engañadas”, “seducidas”, “enamoradas”, “intoxicadas”, “llevadas por la fuerza”, etc., sin llegar a presentar un caso sólido de abuso. Sin negar la verosimilitud de tales afirmaciones, sin duda aquellos dichos

47 AGN, TSJDF, AH-1, c. 3882, fol. 682959, fs. 2v.-3, Eva González de la Sota Riva, aborto (14 de marzo de 1947).

${ }^{48}$ La promesa de matrimonio o esponsales debía hacerse por escrito y no producía la obligación de contraer nupcias, aunque sí sanciones civiles a consideración del juez en función de la falta. Código civil, arts. 139, 142, 143. ${ }^{49}$ Código civil, art. 382. 
evidencian prácticas generalizadas de la época que las mujeres realmente experimentaban, y que en todo caso servían para justificar la pérdida de la virginidad.

Ahora bien, las escasas noticias de mujeres de clases media y alta procesadas por estos delitos se debían con toda seguridad a que ésta podían acceder a técnicas anticonceptivas más efectivas; en caso de embarazarse, podían abortar consiguiendo la asistencia de mejores médicos o parteras, o bien podían dar al niño en adopción; si llegaban a ser aprehendidas, podían financiarse una mejor defensa o incluso intentar corromper a las autoridades. La médica Ofelia Domínguez Navarro comentaba: "si se realiza un estudio detenido de los casos de aborto que nos presentan las estadísticas criminales y penitenciarias, llegaremos a la conclusión de que en su totalidad se han practicado entre mujeres que, debido a su situación económica, no han podido eludir la acción de la justicia"..$^{50}$

Ahora bien, Rodríguez Cabo aseguraba que la interrupción del embarazo era una práctica más recurrida entre las clases populares por motivos económicos y, en menor medida, por la persistencia de prejuicios sociales y religiosos entre mujeres de la clase media. ${ }^{51}$ Evidenciar con un embarazo una sexualidad activa fuera del matrimonio era una gran falta. Una joven escribió en su diario: "estoy embarazada y para mí es sumamente penoso ya que no estoy casada" ${ }^{52}$ De acuerdo con Martha Eva Rocha, la ética católica señalaba para las jóvenes "dos únicos caminos posibles: el de la felicidad, si acatan las normas, y la infelicidad, si adoptan actitudes de rebeldía, de ahí que las conductas transgresoras las vivieran las mujeres con grandes culpas", que en ocasiones se traducían en la comisión de delitos. ${ }^{53}$ Respecto

50 Domínguez Navarro, "El aborto”, p. 368.

${ }^{51}$ Rodríguez Cabo, "El control”, p. 207.

52 Referencia tomada de Rocha, "Los comportamientos", p. 130.

53 Rocha, "Los comportamientos", p. 130. 
a procesadas de clase alta por infanticidio, solo se tiene noticias del mencionado caso de la estadounidense Vera Hunt.

En los diarios los redactores no tenían reparo alguno en denostar de manera altamente exacerbada a las mujeres que transgredían el "mandato" de la maternidad, y veían con similar escozor a quienes abortaban, a infanticidas y a abandonadoras. La causa de ello era, según muchas notas, la mal entendida modernidad, esto es, mujeres que ya no deseaban cumplir con sus obligaciones mujeriles. Así, tras la detención de "La descuartizadora de la Roma”, el diario Excelsior, que se jactaba de ser el defensor nacional de la maternidad, ${ }^{54}$ afirmaba que el verdadero problema de los abortos y los infanticidios radicaba en los cambios sociales que acontecían en el país y, aunque aseguraba que el fenómeno de la "modernización” se extendía por todo el mundo, consideraba que en México la situación era más grave por "las mal entendidas actitudes y ejemplo pernicioso de disolución, concupiscencia y libertinaje". ${ }^{55}$

En general, los sectores conservadores asumían que la "contaminación del espíritu femenino”-consecuencia de la modernización y de los cambios sociales, políticos, económicos y sociales que experimentaba el país y que beneficiaban a las mexicanas- provocaba en ellas conductas sexuales inmorales de las que resultaban embarazos no deseados, por lo que se veían en la necesidad de abortar, de matar al recién nacido o de abandonarlo.

Respecto a los especialistas, de acuerdo con Beatriz Urías, si bien las preocupaciones eugenésicas posibilitaron la discusión del aborto (entre otros temas, como educación sexual, anticoncepción, maternidad responsable, incluso divorcio), muchos

54 El 10 de mayo de 1922 Excelsior sugirió festejar por primera vez a las madres. Para una mayor comprensión de la creación de este concurso y la labor de este diario en torno a la maternidad véase ACEvedo, “10 de mayo", p. 40, y SANTILlÁN EsQUEDA, "El discurso tradicionalista”, pp. 90-110.

55 “Perspectiva”, Excelsior (18 abr. 1941), 1ª sección, p. 4. 
médicos se pronunciaron públicamente a favor del mismo, pero lo condenaban si la gestación era producto de un "desliz". ${ }^{56} \mathrm{~A}$ pesar de que se podía pensar en la interrupción del embarazo como una posible herramienta para mejorar la calidad de la población -e incluso para evitar posibles infanticidios y abandonos-, el papel de la madre quedó "circunscrito a la generación de ciudadanos sanos en el marco de una estricta moral sexual". ${ }^{57}$

Las voces al respecto eran variadas y diversas. Alfredo Saavedra, al igual que otros de sus colegas, no condenaba el aborto precisamente porque atentara contra el ideal femenino o el modelo de familia, lo consideraba "delictuoso porque ataca por medio del asesinato alevoso la vida de un nuevo ser, que la Naturaleza pone en un vientre fecundo". No obstante, Saavedra reconocía que, dadas las circunstancias que se vivían en la época, era necesario que el gobierno promoviese una "maternidad consciente" mediante la promoción de "métodos anticoncepcionales" que ayudaran a evitar embarazos no deseados por cuestiones de "miseria, prole numerosa, enfermedades, defectos físicos o mentales transmisibles por herencia"; para el especialista, evitar "la unión de óvulo y zoospermo" ayudaría a disminuir "los peligros del aborto y del infanticidio". ${ }^{58}$

Por su parte, las médicas Rodríguez Cabo y Domínguez Navarro no suponían que la suspensión de la gestación fuese consecuencia del comportamiento femenino contaminado por la modernidad:59 ${ }^{59}$ or el contrario, reconocían que era una actividad de muy larga data y proponían eliminar el aborto del catálogo de delitos. Rodríguez Cabo insistía en que el uso de métodos para evitar la concepción ayudaría a mejorar las condiciones de

\footnotetext{
56 URÍAs Horcasitas, “Eugenesia y aborto”, pp. 309-318.

57 Urías Horcasitas, Historias secretas, p. 155.

58 SAAvedra, “Aborto criminal”, pp. 626-628.

59 Para conocer un poco más sobre el pensamiento de estas autoras puede revisarse CANO, “Una perspectiva”, pp. 362-372, y SosEnSKI y SosENSKI, “En defensa”, pp. 1-10.
} 
vida de mujeres y niños, principalmente de sectores vulnerables. Asimismo, aseguraba que al permitir la interrupción de los embarazos se evitarían problemas de salud física y mental en mujeres que se enfrentaban con embarazos no deseados, y se frenaría el inescrupuloso comercio de esta actividad que dejaba "un elevado porcentaje de muertes" o terribles secuelas físicas en quienes no perecían. ${ }^{60}$

Sin embargo, a pesar de todas aquellas discusiones, las autoridades no instrumentaron verdaderos mecanismos de apoyo para mujeres embarazadas en condiciones adversas económicas o sociales. En contraparte, hay indicios de incursiones policíacas en consultorios médicos. La agente encubierta de la policía judicial, Esther Medina, se hizo pasar por paciente del doctor Manuel González; tras corroborar las actividades “ilícitas" que ahí se llevaban a cabo, se procedió a la aprehensión in fraganti del galeno y 20 mujeres más. De éstas solo se procesó a dos: Teresa Fernández y Amalia Sánchez García.

La primera, una secretaria de 19 años, en su testificación preliminar ante la policía judicial afirmó que el médico había aceptado ayudarla puesto que había sido víctima de abuso sexual y no quería que "su señora madre se cerciorara de lo que le había pasado"; afirmó que el especialista le introdujo en el conducto vaginal un "pedazo de palo grueso" para que se efectuara la "expulsión del feto". Más adelante declaró que había visitado al doctor porque tenía problemas con su embarazo mas no para abortar, que si perdió a su hijo fue por el trato que le dieron las autoridades tras su aprehensión. El día de la detención, los médicos legistas le extrajeron, en las mismas oficinas del juzgado, un taponamiento vaginal realizado por González; diez

60 Rodríguez Cabo, “El control”, p. 207. Cabe destacar que a partir de 1922 en el estado de Yucatán el aborto por motivos económicos fue permitido siempre y cuando la mujer previamente hubiese dado a luz a tres hijos: Código penal del estado de Yucatán, art. 393, frac. Iv. Véase Islas de GonZÁlez MARISCAL, "Evolución del aborto", pp. 1313-1341. 
horas después llegó al Hospital Juárez, según el reporte médico, "caminando por su propio pie y con hemorragia [...] entre las ropas de la enferma un producto muerto del sexo masculino [...] unido a la placenta por el cordón umbilical" y una "sonda nélaton". Tres semanas más tarde falleció en el hospital a causa de septicemia postaborto. ${ }^{11}$ Por su parte, Amalia, quien el mismo día de la detención había abortado, fue liberada cinco meses más tarde ya que demostró con aval médico que la intervención de González -autorizada por su esposo- era indispensable para resguardar su delicado estado de salud.

En síntesis, en la comisión de estos crímenes se evidencia la existencia de complicaciones experimentadas por las procesadas ante la obligación que pudiera implicar la llegada de un hijo, situación motivada generalmente en los casos de aborto tanto por cuestiones pecuniarias como por la necesidad de encubrir relaciones ilícitas; $y$ en los de infanticidio, fundamentalmente por razones económicas. Con todo, a pesar de que existían voces de especialistas reconociendo los contextos de miseria de muchas procesadas, en el terreno tanto de lo penal como de lo social se consideraba la pérdida de la virginidad como un motivo importante en la comisión de estos delitos. No obstante, mientras socialmente podrían ser tratadas con bastante desprecio, judicialmente podían recibir ciertas consideraciones aquellas mujeres que hubiesen delinquido para cubrir una deshonra.

\section{RECHAZO DE LA OBLIGACIÓN MATERNA:}

ABANDONO DE INFANTES

La Prensa relataba en 1948 la historia de un recién nacido que fue encontrado en la terraza de una casa en la colonia Roma, y "como nadie se quiere hacer cargo de él", fue llevado con las

${ }^{61}$ AGN, TSJDF, AH2, c. 347, exp. 55, f. 109v., Manuel González de la Vega y Amelia Sánchez García, aborto (9 de mayo de 1941). 
autoridades para que lo enviaran a la Casa Cuna; se sospechaba, aseguraba el redactor, de una mujer desconocida que horas antes había tocado varias puertas pidiendo que recibieran al niño que llevaba en brazos. ${ }^{62}$

Respecto a este delito son escasas las referencias judiciales y carcelarias, aunque bastantes las alusiones periodísticas. ${ }^{63} \mathrm{La}$ nota roja daba cuenta de niños abandonados y, en ocasiones, notificaba la aprehensión de algunas madres; y aunque no brinda información sobre el proceso penal y el castigo recibido, proporciona algunos indicios sobre los patrones en torno de dichas prácticas. Los motivos para deshacerse de un hijo en muchos de los casos eran muy similares a los que enfrentaban mujeres que optaban por el aborto o el infanticidio: falta de apoyo del progenitor, precaria situación de subsistencia, necesidad de ocultar el nacimiento, no querer asumir la responsabilidad moral y económica del hijo, o la esperanza de que el crío tuviera una mejor vida.

Incurrían en este delito quienes abandonaban a "un niño incapaz de cuidarse a sí mismo o a una persona enferma, teniendo obligación de cuidarlos"; se castigaba con entre un mes y cuatro años de prisión, y se privaba de la patria potestad o tutelar. Cuando a consecuencia del abandono resultaba alguna lesión o muerte, el victimario debía ser perseguido también por estos delitos en calidad de premeditados. ${ }^{64}$ Es decir que, a la acusación por abandono, si el crío fallecía se podía sumar otra por infanticidio (cuando el nacido tenía menos de 72 horas de vida) u homicidio agravado; en caso de que sobreviviera, se le podía procesar por estos crímenes en grado de tentativa.

Existían dos circunstancias preponderantes en torno a este crimen. La primera, cuando los infantes abandonados tenían

62 "Desnaturalizadas madres abandonaron a sus hijos", La Prensa (21 oct. 1948), pp. 16, 22.

${ }^{63}$ Tenemos dos procesos en los cuales las acusadas pertenecen a sectores bajos.

${ }^{64}$ Código penal, arts. 335, 339 y 343. 
serias probabilidades de fallecer. Por ejemplo, La Prensa relató el rescate de una bebé de 15 días dejada en las vías del tranvía en Tlalpan y Xola por "la mujer que la trajo al mundo, bestia sin entrañas". ${ }^{65}$ Otra recién nacida fue depositada en un basurero de la colonia Roma por "una madre sin escrúpulos o una cómplice de ella"; fue encontrada con vida y trasladada a la Cruz Roja, sin embargo, unas horas más tarde murió. ${ }^{66}$

A diferencia del infanticidio, esta forma de abandono radicaba en que no mataban directamente al hijo; muy probablemente, ante la falta de voluntad para asesinarlo optaban por dejarlo en circunstancias que provocarían su seguro deceso. Hemos señalado que el infanticidio era resultado de situaciones desesperadas para las victimarias; en cambio, las acusadas por este tipo de abandono "mortal”, quizá conseguían ocultar el alumbramiento y se inclinaban por dejar al neonato a "su suerte". ${ }^{67}$

La segunda circunstancia concerniente al abandono solía darse cuando la madre renunciaba, por diversos motivos, a proseguir con la responsabilidad de la crianza del infante (desde su nacimiento o, incluso, siendo mayores), pero lo dejaba en una situación de mucho menor peligro. Algunos niños eran dejados a hurtadillas en lugares relativamente seguros, como puertas de casas, iglesias, asilos, hospitales o incluso en manos de algún conocido o vecino. Así lo resolvió una mujer que rentó una habitación del hotel Torres Quintero; llevaba en brazos a una niña de dos meses de edad -“su hijita", a decir de La Prensa-.

65 “Dramático rescate de una nena abandonada...”, La Prensa (31 jul. 1954), p. 23.

66 "Infame madre, abandonó a su hijita en un basurero", La Prensa (26 ene. 1947), pp. 12, 25.

${ }^{67} \mathrm{Al}$ igual que sucedía en la Argentina de fines del siglo XIX, consideramos factible que hubiese madres que tras haber logrado ocultar su embarazo podían considerar arriesgado dejar a sus hijos en casas de niños expósitos ya que podrían ser descubiertas, por lo que optaban por matarlos o dejarlos en cualquier lugar. Ruggeiro, "Not guilty”, p. 153. 
La supuesta madre salió "a comprar unas medicinas" y pidió al encargado que vigilara a la niña, pero no volvió. ${ }^{68}$

El sector social al que pertenecían este tipo de acusadas generalmente era bajo, de modo que en muchas ocasiones la precaria situación económica era el motivo que subyacía detrás de este delito, aunado a la falta de apoyos familiares e institucionales, como las guarderías del Instituto Mexicano del Seguro Social (creado en 1943), que solo beneficiaban a las trabajadoras o a las esposas de trabajadores.

Es por ello que varias de las acusaciones provenían de vecinos o allegados a quienes las abandonadoras habían dejado a sus hijos por algún tiempo. La señora Esperanza Esparza dio alojamiento a Magdalena García junto con sus hijos de dos y cinco años, pues "no tenía donde vivir y se encontraba sin trabajo". Todos los días Magdalena salía a buscar empleo; al cuarto, dejó una nota que decía "le dejo a mis hijitos. Usted sabe lo que hace con ellos" y no volvió. ${ }^{69}$ Casos como éste evidencian las dificultades que las madres solteras enfrentaban para sostener a sus hijos, y que los discursos de ensalzamiento de la maternidad o políticas públicas de apoyo a la familia en la práctica no alcanzaban a cubrir las necesidades de muchas mexicanas.

Ciertamente, durante el cardenismo se habían fortalecido y expandido programas e instituciones para la protección de la infancia y de apoyo a la maternidad, esfuerzo al que dio continuidad y difusión el gobierno de Ávila Camacho. ${ }^{70}$ Susana Sosenski da cuenta de que desde la creación del Tribunal para Menores, en 1926, "las familias populares utilizaron y negociaron" con esta institución, apropiándose "de discursos y concepciones elaboradas desde arriba para conseguir desde alimentación y techo hasta educación y la formación en algún

\footnotetext{
68 “Abandonó a su hijita en un hotel”, La Prensa (19 jul. 1941), p. 16.

69 "Abandonó a sus hijos en la casa donde...", La Prensa (11 mar. 1949), pp. 19 y 23.

70 Blum, Domestic Economies, pp. 171-179.
} 
oficio para sus hijos". ${ }^{71}$ Es posible que algunas madres hayan acudido a estas instituciones sin que les hubieran recibido al infante; como sea, dejarlos en manos de alguien podía ser una manera expedita -y ciertamente una práctica más común y de larga data- para resolver su situación sin tener que enfrentar los mecanismos institucionales. No obstante, para los años que nos ocupan, las autoridades buscaban regular con incipiente éxito dichas prácticas en aras de fortalecer a la familia, en la que la madre debía ser la responsable de la crianza de los hijos.

En algunos casos las dificultades económicas no se aprecian como la causa principal; incluso, algunas victimarias contaban con el soporte económico y moral del padre o de allegados. Había mujeres que se alejaban de sus hijos por desprecio a los progenitores de sus hijos o porque buscaban un tipo de vida que era difícil empatar con la vida familiar. El pastelero Guillermo García Morillo se presentó en las oficinas policíacas con su hijo de seis meses en brazos, "bastante enfermo por la falta de un alimento adecuado [leche materna]" para denunciar la ausencia de su mujer. Finalmente fue encontrada en casa de unos familiares, pero ella dijo que "no le importaba el niño, ya que de atenderlo, por fuerza tendría que volver a hacer vida marital". ${ }^{72}$ Por su parte, Imelda Rubí aprovechó que su esposo estaba internado en el hospital para salirse de casa de su cuñado y regalar a su hijo, pues se mostraba "dizque modernista, terminando por decirle [al marido] que quizás ya no vivirían juntos [...], pues quería ser libre para vivir al lado de un chofer y divertirse como nunca lo había hecho". ${ }^{73}$

Como se ha insistido, en el periodo circulaba una concepción negativa respecto al ser mujer moderna, "liberada", es decir, aquella que supuestamente renegaba de los valores y

71 Sosenski, El trabajo infantil, p. 384.

72 “Abandonó al hijo una impía mujer”, La Prensa (3 abr. 1945), pp. 12-13.

73 Regaló al hijito desalmada mujer”, La Prensa (3 nov. 1946), pp. 12, 21. 
obligaciones tradicionales considerados propios de su sexo; esto es, que daba preferencia a otras formas de realización personal (estudio, trabajo, diversión) más allá del hogar, el matrimonio y la procreación. De ahí que los redactores de los diarios adjetivaran constantemente a las acusadas como modernas. La sirvienta Antonia Herrera fue a un baile junto con otras empleadas y dejó a su hija en la casa donde laboraba. Sus compañeras volvieron, pero ella se fue con Mario López a un hotel en Tacubaya; declaró haber tardado en volver porque no tenía dinero para el camión. Cuando finalmente volvió, a las pocas horas nuevamente se fue al Salón México, donde fue aprehendida tres días después. ${ }^{74}$

No hay indicios judiciales o periodísticos de mujeres pertenecientes a la clase media o alta procesadas por abandono. Este tipo de madres contaba, sin duda, con más recursos económicas para dejar a sus hijos al cuidado de familiares, nanas, servidumbre, internados, guarderías, incluso para darlos en adopción o para "regalarlos" evitando el conocimiento de las autoridades. En todo caso, entre estos sectores sociales el principal motivo para deshacerse de un hijo llegaba a encontrarse en cuestiones de orden moral. Así lo sugiere el filme La señora de enfrente (Gilberto Martínez Solares, 1945). En esta historia de Rómulo Gallegos, los Cortazano son una familia acomodada de provincia; los padres obligan a su hija Lastenia (Sara García) a regalar a su recién nacida, producto de una relación amorosa fuera del matrimonio. Con los años, la protagonista se convierte en una solterona amargada que constantemente maquinaba intrigas que involucraban a todos los habitantes del lugar. Cierto día una joven llamada Gilberta arribó al pueblo; iba en búsqueda de su verdadera madre pues sospechaba ser adoptada. Al descubrir que Lastenia era su madre biológica, se evidencia también que

${ }_{74}$ AGN, TSJDF, AH-2, c. 332, exp. 83, fs.1-3, Antonia Herrera, abandono de persona (21 de noviembre de 1949). 
la hostilidad de ésta había sido producto de la frustración por haber repudiado a su hija.

El delito de abandono se denunciaba poco, ello en un contexto en que era habitual que los niños renunciados llegaran a ser aceptados y criados por quienes se los encontraban o los recibían. Ann S. Blum comenta que aún en los años cuarenta, gracias a "redes informales [se] siguieron transfiriendo niños a través de las barreras de clase"; normalmente los patrones recibían como "regalo" el hijo de alguna mujer que había estado a su servicio. Esto era común, agrega la autora, porque la adopción era todavía una novedad y continuaban vigentes los medios informales para la adquisición de infantes. ${ }^{75}$ Por ejemplo, en el Hospital General, a cambio de 300 pesos la señora Camacho recibió a una recién nacida, pues los progenitores alegaron que ya "tenían dos y estaban muy pobres". La compradora actuó de tal forma "para atraer nuevamente a su esposo"; sin embargo, éste la denunció ya que no hacían vida marital y era imposible su paternidad. ${ }^{76}$ Los hospitales eran sitios muy recurridos para el traspaso de infantes, como se notará en diversos ejemplos reseñados en el siguiente apartado.

Al igual que en los delitos de aborto y de infanticidio, los recursos económicos y sociales marcaban las dinámicas y tendencias del delito de abandono de infante. Las mujeres de las clases mejor avenidas son menos procesadas y sus motivaciones se presumen fundamentalmente del orden moral más que económico. Estas delincuentes, además de transgredir el orden penal, atentaban contra el estereotipo de la madre amorosa y realizada como mujer gracias a la crianza. No obstante, hay otra práctica en la que el afán de apegarse al ideal materno lleva a las mujeres a delinquir.

75 Blum, “Haciendo y deshaciendo”, p.217.

76 “Maniobra de una casada”, El Universal (31 ene. 1942), 2ª sección, p. 1. 
EL CRIMINAL DESEO POR SER MADRE:

ROBO DE INFANTES

El jefe de la policía metropolitana, general Ramón Jiménez Delgado, estimaba que "no existen bandas organizadas de robachicos, sino que se trata de hampones diseminados, delincuentes esporádicos u ocasionales que aprovechan alguna circunstancia fortuita para atentar contra los pequeñuelos a quienes sus familiares no custodian debidamente". Aun cuando no hay datos que permitan constatar las cifras de robo de niños, en la época existía un "grave estado de alarma social" frente a este crimen, ${ }^{77}$ noción ligada al crecimiento urbano y a la gran ciudad vista muchas veces como espacio hostil e impersonal.

En un periodo de diez años la sanción aplicada a este delito aumentó en tres ocasiones, lo cual indica un creciente repudio de dicha práctica en el marco de las preocupaciones por los niños y la implementación de mecanismos institucionales en apoyo a la infancia. El código penal castigaba con entre 5 y 20 años de prisión y una multa de 100 a 1000 pesos a quien plagiara o secuestrara a un infante menor de siete años si era un extraño a la familia de éste. En 1946 llegó la primera modificación: “el robo de infante, menor de 10 años, se castigará con prisión de 10 a 30 años"; en 1951 aumentó, una vez más, la edad del infante plagiado a 12 años; en 1955 una reforma en la legislación penal señalaba que el máximo de una sanción corporal sería de 40 años; al mismo tiempo se extendió a este tope el castigo por robo de infante, equiparado con el homicidio calificado. ${ }^{78}$

Las mujeres tenían una importante función en la práctica de este delito, pues se acercaban a los niños utilizando sus "atributos femeninos" de ternura y afición por los infantes. Herlinda

77 “Se intensifica la batalla contra los robainfantes", La Prensa (16 nov. 1945), pp. 2, 38.

${ }_{78}$ Legislación penal, art. 366-fracc.V. 
Rivero González dio a luz en el Hospital Juárez, donde conoció a María Concepción Arellano, quien visitaba y llevaba regalos a las enfermas. Un día le dijo que "le gustaba mucho [su hijo] para que fuera su ahijado y que si no quería que fuera su comadre". La madre de Herlinda contaba que días más tarde la acusada "se presentó a su domicilio con ese objeto y su hija que es muy tonta le dio al niño para que se lo bautizara", sin que se volviera a saber de ella. ${ }^{79}$

La persecución de estas criminales y la recuperación de los infantes resultaba una labor complicada para las autoridades, pues normalmente lograban huir sin que hubiera señas suficientes para localizarlas. La señora María Álvarez Rodríguez tardó 18 años en encontrar a la mujer que se robó a su hijo Rafael de un año de edad. En 1923, María Téllez Chavarría, de 12 años, se colocó como sirvienta en casa de María Álvarez. A los 12 días, la empleada salió con el pequeño y no volvió más. Siguiendo posibles pistas, la madre levantó denuncias en Sinaloa, Hidalgo y Puebla; y a lo largo de todos esos años estuvo al tanto de la infructuosa búsqueda. En 1940, leyó una nota periodística que informaba sobre unos hombres de aproximadamente 18 años que habían asesinado a una mujer en la ciudad de Pachuca; al creer que uno de los criminales podía ser su hijo Rafael, se dirigió a esa ciudad para instar a las autoridades a reiniciar la búsqueda. Ninguno de los asesinos resultó ser su hijo, sin embargo, se localizó y detuvo a la plagiaria María Téllez.

Al ser trasladada a la ciudad de México, la acusada declaró que en aquel entonces era muy joven y no conocía bien la capital, así que cuando salió con el niño Rafael no supo cómo volver; decidió marcharse a Pachuca con un profesor conocido que encontró en la calle. Un mes después, éste la dejó y ella se fue a buscar trabajo a las minas de Real del Monte con su nuevo

79 AGN, TSJDF, $A H-2$, c. 364, exp. 25, fs. 1 y 5, María Concepción Arellano, robo de infante (15 de enero de 1942). 
amasio, Antelmo. Ahí el niño murió; Antelmo se llevó el cadáver y no volvió, por lo que no supo más del asunto. María regresó a Pachuca, donde se empleó como doméstica y, una vez más, se fue del domicilio con el hijo de sus nuevos patrones. No obstante, en esa ocasión los padres recuperaron al niño; las autoridades aprehendieron a la plagiaria en Malila, un pueblo ubicado en una zona boscosa del estado de Hidalgo. María aseguró que se había quedado en Malila porque "la época de lluvia estaba muy fuerte y no quería que el niño se mojara”. ${ }^{80}$

Finalmente, María no fue procesada por el secuestro de Rafael, el hijo de la señora Álvarez, ya que el juez de instrucción enunció extinta la acción penal. De acuerdo con el código, toda acción penal se suprimía cuando el acusado no era localizado antes del tiempo establecido por el término medio aritmético de la sanción correspondiente a cada delito. ${ }^{81}$ En el caso de robo de infante, 12 años era lo indicado por dicha fórmula; para la fecha en que se detuvo a María, 18 años después del plagio, el proceso tenía seis de haber sobreseído.

De nuestras procesadas, tres eran domésticas, tres tortilleras, dos amas de casa, una costurera, una cabaretera y una estaba prófuga. Las verdaderas motivaciones para robar un infante podían ser diversas y normalmente eran oscurecidas por las criminales; aunque, en general, justificaban su accionar como resultado de un impulsivo deseo maternal. Juana Sánchez confesó haberse robado el hijo de cinco años de la señora Loreta García de Barbosa porque "carece de hijos"; no obstante, aseguró que "dos señoras desconocidas" se lo "arrebataron [...] ignorando finalmente el paradero del pequeño". ${ }^{82}$ En otro caso una partera procedente de Hidalgo encontró a una mujer con

${ }^{80}$ AGN, TSJDF, AH-2, c. 339, exp. 60, f. 5, María Téllez Chavarría, robo de infante (29 de diciembre de 1940).

${ }^{81}$ Código penal, art. 118.

82 "Plagiaron un niño en las calles de Uruguay", La Prensa (25 nov. 1950), p. 26. 
un recién nacido frente a una clínica en la colonia Del Valle y le dijo que por indicación del doctor debía dárselo para llevarlo a revisión; al tenerlo bajo su posesión huyó con él. La partera había concretado la venta de un niño con una mujer que pretendía engañar a su esposo diciéndole, para reconciliarse con él, que había parido. ${ }^{83}$

Hay plagios en los que se expresa abiertamente la necesidad de las mujeres de hacerse pasar por madres, ya sea para engañar a sus parejas o para construirse una imagen ante la sociedad. Centraremos la atención en estos casos, en tanto que son transgresiones penales y sociales que suceden por el afán de las procesadas de apegarse al ideal femenino. En marzo de 1942 El Universal narraba con beneplácito la restitución de la niña María Luisa a su verdadera madre, Marcelina, en tanto se condenó a cinco años de prisión a la ladrona, Consuelo Pérez. La delincuente sostuvo hasta el último momento del juicio penal que la menor era hija suya y de su esposo; no obstante, gracias a los "modernos métodos" anatomopatológicos del tipo de sangre, alardeaba el diario, se descubrió que ella no era la progenitora. ${ }^{84}$ En el expediente judicial consta que los peritos sumaron a esta prueba el estado dentario y el desarrollo psicomotor de la niña. Ocho meses antes, Consuelo le arrebató de los brazos a la niña a Marcelina mientras platicaban en la calle.

Cuatro meses después, Marcelina vio a la plagiaria en la calle y se logró su detención. El amasio de la acusada declaró que siempre dudó que la niña fuese su hija pues la veía muy desarrollada (para entonces tenía ya poco más de 2 años). No obstante, Consuelo sostenía fehacientemente que tenía nueve meses de edad, asegurando que se veía desarrollada porque era

83 "Mujer que roba a un niño para venderlo", El Universal (10 mayo 1941), $2^{a}$ sección, pp. 1, 12.

84 “Un niño se disputaban dos mujeres”, El Universal (20 mar. 1942), $2^{\mathrm{a}}$ sección, p. 1. 
sietemesina, había aprendido a caminar muy pronto y recientemente le habían salido todos los dientes. ${ }^{85}$

Pichardo creía que cuando no existían expresos "impulsos de codicia", este crimen era "típicamente femenino" puesto que buscaba "satisfacer una maternidad defraudada"; situación que, obviando el daño causado, debía generar compasión por las victimarias. Agregaba, incluso, que era cometido por mujeres de "suma ignorancia o mínimos recursos que les impiden recurrir a una fórmula legal de la adopción". ${ }^{86}$ Sin embargo, tales ideas de Pichardo no tomaban en cuenta que la realidad era mucho más compleja; en principio porque, como hemos comentado, los sistemas de adopción legal aún estaban en ciernes y no eran sencillos. ${ }^{87}$ Lo cierto es que en general este tipo de delincuentes eran vistas con cierta consideración, tanto por criminólogos como por la prensa; ello bajo el entendido que se asumía cada vez más de que la razón de la existencia femenina era la maternidad.

La Prensa relató "el punzante drama" de María del Carmen Mariñelarena, una taquimecanógrafa de 22 años de edad. La joven, de clase media, había logrado la reconciliación con su exesposo tras anunciarle su embarazo; no obstante, a los pocos días de nacida su hija denunció a las autoridades que un hombre desconocido se bajó de un auto y le arrebató a la niña. La policía comenzó las pesquisas en casa de Josefina Montoya, exempleada doméstica del matrimonio. Ahí se descubrió que María del Carmen le había pedido a Josefina a su bebé prestado por unas semanas; se la presentó a su marido como propia y la registraron civilmente. Para recuperar a su hija, Josefina amenazó a su expatrona con decir la verdad. Entonces, María del Carmen se vio en la necesidad de fingir el secuestro para devolvérsela a Josefina. La acusada no se consideraba una mala mujer, y creía

${ }_{85}$ AGN, TSJDF, AH-2, c. 334, exp. 84, Consuelo Pérez Juárez, robo de infante (21 de julio de 1941).

86 Pichardo Estrada, "Criminología y delincuencia", p. 174.

87 BLum, "Haciendo y deshaciendo". 
demostrarlo con los buenos tratos que prodigó a la niña, así como por haberle dado "leche de buena calidad". Respecto a su esposo comentó: "ignoro qué actitud va a asumir. Pero, de todos modos, lo quiero y lo seguiré queriendo, aun cuando él me aborrezca para siempre". ${ }^{8}$

Parece ser que en la época para muchas mujeres era verdaderamente una desgracia no ser madre. Ello se entiende en el marco de una sociedad en la que la realización femenina se lograba fundamentalmente en virtud de la maternidad y lo que ello conllevaba: satisfacer tal deseo en sí mismo, formar una familia, retener a un hombre y ser respetada socialmente. Por ejemplo, La Prensa relataba "el amargo drama de una mujer sin hijo”, Sofía Solano de Vázquez, quien intentó suicidarse. ${ }^{89}$ Tal desesperación por cumplir sus "deseos maternales" llevaba a varias mujeres, fundamentalmente de sectores medios o mejor avenidos, a aceptar uno regalado, comprándolo, robándolo o por medio de adopciones ilegales.

Uno de los casos más célebres de la época fue el secuestro en octubre de 1945 del niño Fernando Bohigas, hijo de un importante comerciante. El señor Bohigas colaboró con la policía en la búsqueda de su hijo, se transmitieron anuncios en la radio y ofreció 10000 pesos de recompensa. Ocho meses más tarde, en la zona de La Lagunilla, un agente policiaco vio asomarse a un niño rubio por la ventana de una casa; le resultó sospechoso que el infante no saliera a jugar y que no tuviese parecido físico a las personas que ahí habitaban. María Elena Rivas fue detenida junto con su esposo, Carlos Martínez Maldonado, quien aseguró no saber nada del secuestro. La acusada dijo que "el niño me gustó desde que lo vi, además la señora tiene muchos. ¿Qué más le da tener uno menos?". ${ }^{90}$ Es importante anotar que la primera

88 "Punzante drama de una esposa enamorada y madre sin...", La Prensa (24 nov. 1953), p. 29.

89 "El amargo drama de una mujer sin hijo", La Prensa (1 dic. 1946), p. 12.

90 Luna, La nota roja, pp. 127-133. 
modificación hecha al código penal, en la que se aumentó la sanción por robo de infante, se realizó a partir de este caso. Durante los siguientes años, la nota roja emulaba este caso con el de otras ladronas de infantes, sobre todo cuando el motivo era satisfacer los deseos maternales. Incluso, en alusión a este secuestro se realizó la película ; Ya tengo a mi hijo! (Ismael Rodríguez, 1948) que protagonizaba el verdadero niño Bohigas.

Hay varios registros en prensa de mujeres solteras, pertenecientes a los sectores medios y que contaban con los recursos suficientes para sostener al infante robado, que expresaron como motivo principal el deseo de ser madre. Margarita Porras Méndez, de 21 años de edad, residía en Acapulco y trabajaba como secretaria y contadora para un millonario inversionista estadounidense quien era vecino de la familia Zuluoga. Margarita trabó amistad con los Zuluoga y se ganó el cariño del pequeño Jaime de seis años de edad. Un día, Margarita desapareció con Jaimito; fue detenida en el Distrito Federal. Según La Prensa, la delincuente declaró que se lo había llevado por unos días, ${ }^{91}$ pues solamente pretendía presumir a sus amigas que "pese a sus constantes burlas de que no se casaría nunca, ella tenía un hijo”. Hacía tiempo que les escribía contándoles sobre su hijo, e incluso les prometió que un día lo llevaría a la ciudad de México para que lo conocieran. ${ }^{92} \mathrm{El}$ redactor del diario no creía que Margarita fuese una “vivales”, por el contrario, la consideraba una "pobre infeliz que vive fuera de la realidad, creyendo que puede obtener, a la hora que le viene en gana, un niño que le haya gustado". ${ }^{93}$

Por su parte, Amparo Salinas Fernández era cliente asidua de una miscelánea que pertenecía al matrimonio Vázquez Huerta;

91 "Otro plagio como aquel del famoso niño Bohigas", La Prensa (4 jun. 1953), pp. 23, 25.

92 “Deseaba presumir con el niño”, La Prensa (5 jun. 1953), p. 23.

93 "Otro plagio como aquel del famoso niño Bohigas", La Prensa (4 jun. 1953), p. 23. 
cultivó amistad con ellos y se ganó el afecto de su hija Berta de año y medio. En un momento de descuido, tomó a la niña "para tener una hija, ya que Dios hasta ahora se lo ha negado", afirmó la victimaria. Huyó a Guadalajara, donde fue detenida siete meses más tarde. Agregó que no se arrepentía pues quería a Berta como si fuera suya y le pedía a Dios que le diera un hijo "para no tener que robar otro niño"..$^{94}$

Para este tipo de criminales, ser madre resultaba más asequible al apoderarse de un infante antes que embarazarse o adoptar. Probablemente buscaron preñarse sin éxito, o bien, no lo intentaron porque, afines a la moral de la época, condenaban las relaciones sexuales fuera del matrimonio y, a falta de un marido, no estaban dispuestas a tener una cópula ocasional. Aunque también es posible que no les interesara la vida conyugal. En la época existían mujeres que efectivamente deseaban ser madres sin la responsabilidad de un matrimonio; de acuerdo con Blum, mujeres solteras solicitantes de adopción, entre 1938 y 1940, "consideraban que el matrimonio era irrelevante para el deseo de ser madres y tener una vida familiar" ${ }^{95}$ Los procesos de adopción eran complicados y poco exitosos para perfiles como los de Margarita y Amparo. ${ }^{96}$ Blum demuestra que "la aprobación para adoptar favorecía a las mujeres que dependían del ingreso de un esposo y que podían pagar servidumbre" ${ }^{97}$ Las negociaciones sobre las capacidades como madres de las solicitantes se vinculaban, afirma la autora, con las nociones de una niñez protegida por una familia tradicional de clase media y por una madre dedicada por completo al hogar en el marco matrimonial.

94 "Robachicos capturada en Guadalajara", La Prensa (12 nov. 1954), pp. 26-29.

95 Blum, "Haciendo y deshaciendo", pp. 216-217.

${ }^{96}$ El artículo 390 del Código Civil posibilitaba a cualquier mayor de 30 años que no tuviera descendientes adoptar un menor, siempre y cuando la adopción fuese benéfica para éste.

97 Blum, "Haciendo y deshaciendo", p. 198. 
A diferencia de los otros delitos estudiados en el presente trabajo, el robo de infante sí contabilizaba a varias criminales provenientes de los sectores mejor avenidos. Ello se debe, en primer lugar, a que contaban con los recursos materiales para la crianza de los hijos; en segundo, a su afinidad con los extendidos discursos tradicionalistas que aseguraban que la realización femenina de daba por medio de la maternidad, así como a la presión para cumplir con este estereotipo. En cambio, las acusadas pertenecientes a sectores populares en pocas ocasiones dejaban claro los verdaderos motivos del plagio, y parecía que aludían a este argumento como simple justificación; con todo, es bastante plausible que haya habido quienes utilizaran este recurso para ser madres.

\section{REFLEXIONES FINALES}

Los cambios que experimentaba la capital nacional producto de la modernización urbana hacia la década de 1940, generaba inquietud entre los grupos conservadores pues asumían que ello, sumado a las prerrogativas legales otorgadas a las mujeres, las llevaría a desistir de sus obligaciones femeninas, entre ellas, la maternidad.

En dicho contexto, las procesadas por los delitos estudiados adquirían un protagonismo especial signado por esquemas de género que suponían a las mujeres naturalmente inclinadas hacia una maternidad amorosa y abocada a la crianza de sujetos sanos física y mentalmente, pero también resultado de una sexualidad femenina inscrita en el marco conyugal. En tal sentido, es posible observar una serie de elementos sociales y económicos específicos del periodo que enmarcaban la comisión de los delitos de aborto, infanticidio, abandono o robo de infante. Las prácticas criminales en torno a los tres primeros dan cuenta de mujeres que transgredían el ideal materno; en el último se constata la existencia de otras convencidas de que su realización personal 
y social era solo posible al ser madres; así, hay procesadas por robo de infante que por buscar ajustarse al ideal atentan contra el orden penal.

En general, el sector social de las procesadas marca las pautas y las tendencias de estos crímenes. Las mujeres de clases mejor avenidas se suscribían con mayor facilidad al ideal femenino, de ahí que se les procesara penalmente en mayor medida por el delito de robo de infante, en tanto la importancia personal y social que tenía para ellas ser madres. Por otro lado, el hecho de contar con mayores recursos las llevaba a tener más opciones para dirimir un embarazo o la llegada de un hijo no deseado, pudiendo así esquivar la justicia penal.

Respecto a la transgresión al ideal materno, el aborto era una práctica más extendida que el infanticidio y el abandono para solucionar los problemas que pudiera generar la llegada de un hijo, debido en gran medida a que las técnicas abortivas habían mejorado y los servicios de médicos y parteras estaban más extendidos para los años de estudio. Con todo, abortar era un gran riesgo dada la clandestinidad de la práctica, que se ofrecía regularmente en deplorables condiciones de higiene; es por ello que un importante porcentaje de mujeres eran acusadas penalmente tras complicaciones posaborto. Es de notar también que las procesadas por abortar solían contar con más recursos económicos y redes comunitarias de apoyo que las infanticidas. Éstas, y en muchos casos las abandonadoras, solían ser pobres, marginadas y más vulnerables socialmente.

La vida cotidiana de este grupo de mujeres se percibe mucho muy difícil: abusos sexuales (en ocasiones en sus propios lugares de trabajo), necesidad de conservar un empleo, falta de apoyo familiar, abandono del progenitor, rechazo social por el embarazo. En este sentido, es posible dar cuenta de una serie de circunstancias sociales difíciles de empatar con el ideal para ellas, en donde la sobrevivencia económica las hacía encontrar en el crimen su mejor opción. Esto en una sociedad que, al conferirle 
un carácter político y moral a la maternidad, impulsaba la creación de instituciones de apoyo a la infancia y a las madres, pero que estaban lejos de poder satisfacer las necesidades de todas las mexicanas.

En contraparte, lo que se observa en las visiones, tanto de la prensa como de los especialistas médicos y criminólogos -salvo contadas excepciones, como los casos de las médicas Rodríguez Cabo y Domínguez Navarro-, es una mirada conservadora que, en el contexto de una época de transformaciones sociales y políticas, opta por defender una sexualidad femenina legitimada por el matrimonio y que denigra con mucha facilidad las conductas en las que se traslucen prácticas sexuales fuera de esa norma. No obstante, es importante remarcar que la justicia penal reconocía, en particular en los casos de aborto e infanticidio, la posible necesidad de ocultar una deshonra, por lo que podía conceder penas atenuadas. Así, la virginidad y la maternidad eran en aquel contexto social y judicial, de una u otra forma, el nódulo de estas dos prácticas delictivas.

En el caso de las delincuentes, la motivación en la comisión de abortos, infanticidios y ciertas formas de abandono era en menor medida la necesidad de ocultar relaciones sexuales ilícitas, argumento más socorrido por mujeres de clases medias (un elemento más que demuestra su adscripción al ideal femenino). En tal sentido, la marginación, la falta de recursos materiales y sociales para evitar el delito o para defenderse penalmente, provocaba que fueran las mujeres de sectores bajos las más procesadas -y castigadas- por aborto, infanticidio y abandono.

En cuanto al robo de infante, sin negar la posibilidad de que el secuestro de menores fuese parte de redes de explotación laboral o sexual, una motivación importante de plagiarias provenientes de sectores medios era la necesidad personal -engarzada con la presión social- de cumplir el ideal materno, buscando con ello reconocimiento social o retener a un hombre a su lado. En estos casos, y a diferencia de los otros delitos, tanto la prensa como 
los criminólogos podían mostrarse más compresivos, pues a fin de cuentas no transgredían la supuesta naturaleza materna propia de las mujeres.

El creciente culto a la madre en la década de 1940, relacionado con la nueva conciencia política y social hacia los niños, y aunado al papel de los medios de comunicación (como la prensa y el cine), ayudó a la rápida consolidación de la figura de mujeres terribles e inhumanas cuando agredían o asesinaban infantes, al tiempo que existía cierta condescendencia con aquellas que plagiaban niños para satisfacer su deseo de ser madres. Así, el estereotipo de la mujer realizada principalmente por medio de la maternidad y con una sexualidad suscrita al matrimonio se afianzaba fuertemente en estos años. Habría que esperar varias décadas para que comenzara a transformarse de manera más palmaria.

\section{SIGLAS Y REFERENCIAS}

AGN-TSJDF-AH Archivo General de la Nación, fondo Tribunal Superior de Justicia del Distrito Federal, Archivo Histórico, Ciudad de México.

AH-UAER-UNAM-J-MRC Archivo Histórico, Unidad Académica de Estudios Regionales de la UNAM, Jiquilpan, Michoacán, fondo documental Matilde Rodríguez Cabo.

\section{LEYES, CÓDIGOS Y REGLAMENTOS}

Código Civil para el Distrito y Territorios Federales (1932), México, Imprenta Aldina, 1928.

Código Penal para el Distrito y Territorios Federales en materia de fuero común y para toda la República en materia de fuero federal (1931), México, Ediciones Botas, 1936.

Código Penal del estado de Yucatán, México, Imprenta de la Lotería del Estado, 1926. 
Legislación penal y su interpretación por el Poder Judicial, Disco Compacto, México, Suprema Corte de Justicia de la Nación, 2007.

Acevedo, Marta, “10 de mayo”, en Gutiérrez Castañeda (coord.), 2002, pp. 39-51.

Agostoni, Claudia (coord.), Curar, sanar y educar. Enfermedad y sociedad en México, siglos XIX y XX, México, Universidad Nacional Autónoma de México, Benemérita Universidad Autónoma de Puebla, 2008.

Aguirre, Carlos A. y Robert Buffington (eds.), Reconstructing Criminality in Latin America, Wilmington, Delaware, SR Books, 2000.

Azuela, Mariano, "La nueva burguesía”, en Obras completas, México, Fondo de Cultura Económica, 1996, vol. 2, pp. 9-138.

Bermúdez, María Elvira, La vida familiar del mexicano, México, Antigua Librería Robredo, 1955.

Birgin, Haydée (comp.), El género en el derecho penal: las trampas del poder punitivo, Buenos Aires, Biblos, 2000.

Buum, Ann S., Domestic Economies: Family, Work, and Welfare in Mexico City, 1884-1943, Lincoln y Londres, University of Nebraska, 2009.

Buum, Ann S., "Haciendo y deshaciendo familias. Adopción y beneficencia pública, Ciudad de México, 1938-1942", en Cano, Vaughan y Olcott (comps.), 2010, pp. 196-224.

CANo, Gabriela, "Una perspectiva del aborto en los años treinta, la propuesta marxista”, en Debate Feminista, 2 (sep. 1990), pp. 362-372.

Cano, Gabriela, Mary Kay Vaughan y Jocelyn Olcott (comps.), Género, poder y política en el México posrevolucionario, México, Fondo de Cultura Económica, 2010.

CÁrdenas, Salvador y Elisa Speckman (coords.), Crimen y justicia en la bistoria de México, México, Suprema Corte de Justicia de la Nación, 2011.

Castro, Felipe y Marcela Terrazas (coords. y eds.), Disidencia y disidentes en la historia de México, México, Universidad Nacional Autónoma de México, 2003. 
Cruz Salinas, Binisa, "Mathilde Rodríguez Cabo, una luchadora social en México. Pensamiento feminista y activismo político en defensa de las trabajadoras durante la posrevolución”, tesis de licenciatura en historia, México, Instituto de Investigaciones Dr. José María Luis Mora, 2016.

Damián, Gisela y Ana LaU JaIven (coords.), Un fantasma recorre el siglo. Luchas feministas en México, 1910-2010, México, Universidad Autónoma Metropolitana-Xochimilco, Itaca, Consejo Nacional para la Cultura y las Artes, El Colegio de la Frontera Sur, 2011.

Domínguez Navarro, Ofelia, "El aborto por causas sociales y económicas", en Cano, 1990, pp. 362-373.

Fuentes, Carlos, La región más transparente, México, Fondo de Cultura Económica, 2012.

Gonzalbo Aizpuru, Pilar, Historia de la vida cotidiana en México, México, El Colegio de México, Fondo de Cultura Económica, 2006, t. V, vol. II.

Gutiérrez Castañeda, Griselda (coord.), Feminismo en México. Revisión bistórico-crítica del siglo que termina, México, Universidad Nacional Autónoma de México, 2002.

Islas de González Mariscal, Olga, "Evolución del aborto en México", en Boletín Mexicano de Derecho Comparado, 123 (sep.-dic. 2008), pp. 1313-1341.

Jiménez Huerta, Mariano, "Delito de infanticidio", en Criminalia. Revista de Sociología Criminal, xxv:2 (feb. 1959), pp. 106-120.

José Agustín, La tragicomedia mexicana. La vida en México de 1940 a 1970, México, Booket, 2007.

Lau Jaiven, Ana, "Mujeres, feminismo y sufragio en los años veinte", en Damián y Lau Jaiven (coords.), 2011, pp. 61-96.

Luna, Ana Luisa, La nota roja, 1940-1949, México, Grupo Editorial Siete, 1997.

Martos, Ana, Breve historia del condón y métodos anticonceptivos, Madrid, 2012. 
Maza Pesqueira, Adriana (coord.), De liberales a liberadas. Pensamiento y movilización de las mujeres en la bistoria de México (1753-1975), México, Nueva Alianza, 2014.

Muñız, Elsa, Cuerpo, representación y poder: México en los albores de la reconstrucción nacional, 1920-1934, México, Universidad Autónoma Metropolitana-Azcapotzalco, Miguel Ángel Porrúa, 2002.

Núnez Becerra, Fernanda, "De una práctica privada a una sanción pública. La anticoncepción en el porfiriato", en Nuevo Mundo Mundos Nuevos, Coloquios, 2008, enero 2008, http://nuevomundo.revue.org/index14772.html

Núnez Cetina, Saydi, "Reforma social, honor y justicia: infanticidio y aborto en la ciudad de México, 1920-1940”, en Signos Históricos, 128 (jul.-dic. 2012), pp. 68-113.

Pacheco, José Emilio, Batallas en el desierto, México, Era, 2008.

Padilla Arroyo, Antonio, "Infancia en vilo: orfandad y protección", en Padilla Arroyo, Soler, Arredondo, Moctezuma (coords.), 2008, pp. 407-435.

Padilla Arroyo, Antonio, Alcira Soler, Martha Luz Arredondo y Lucía M. Moctezuma (coords.), La infancia en los siglos XIX y XX. Discursos e imágenes, espacios y prácticas, México, Casa Juan Pablos, Universidad Autónoma del Estado de Morelos, 2008.

Pichardo Estrada, Félix, "Criminología y delincuencia femenina”, en Criminalia. Revista de Sociología Criminal, xxII: 3 (mar. 1956), pp. 167-174.

Recéndez Guerrero, Emilia, Norma Gutiérrez Hernández y Diana Arauz Mercado (coords.), Presencia y realidades: investigaciones sobre mujeres y perspectiva de género, México, Taberna Libraria Editores, Universidad Autónoma de Zacatecas, Inmuza, Universidad Autónoma de Nuevo León, Universidad Juárez del Estado de Durango, Universidad de Guanajuato, 2011.

Rocha, Marta Eva, "Los comportamientos amorosos en el noviazgo, 18701968", en Historias. Revista de la Dirección de Estudios Históricos, 35 (oct. 1996-mar. 1996), pp. 119-139.

Rodríguez Cabo, Matilde, "El control de la natalidad", en Archivos de Neurología y Psiquiatría de México. Órgano de la Sociedad Mexicana de Neurologia, t. I (nov. 1937), pp. 198-210. 
Rodríguez CABo, Matilde, "El problema sexual de las menores mujeres y su repercusión en la delincuencia juvenil femenina”, en Criminalia. Revista de Sociología Criminal, vi: 10 (jun. 1940), pp. 543-548.

Rodríguez Raygoza, Elizabeth, “¿Víctimas o victimarias?: infanticidio y conducta criminal en Jalisco, 1867-1873”, tesis de maestría en historia, México, Instituto de Investigaciones Dr. José Ma. Luis Mora, 2004.

Ruggeiro, Kristin, "Not guilty: abortion and infanticide”, en Aguirre y Buffington (eds.), 2000, pp. 149-166.

Rulfo, Juan, El llano en llamas, México, Fondo de Cultura Económica, 2008.

Rulfo, Juan, Pedro Páramo, México, Fondo de Cultura Económica, 2008.

SaAvedra, Alfredo, “Aborto criminal y eugenesia”, en Criminalia. Revista de Sociología Criminal, iv: 10 (jun. 1938), pp. 624-628.

SANTILlán Esqueda, Martha, "Discursos de redomesticación femenina durante los procesos modernizadores en México, 1946-1958”, en Historia y Grafía, 31 (dic. 2008), pp. 103-132.

SANTILLÁn Esqueda, Martha, "El discurso tradicionalista sobre la maternidad: Excélsior y las madres prolíficas durante el avilacamachismo", en Secuencia. Revista de Historia y Ciencias Sociales, 77 (mayo-ago. 2010), pp. 90-110.

Santillán Esqueda, Martha, "Infanticidas en la ciudad de México (19401950), representación y realidad”, en Recéndez Guerrero, Gutiérrez Hernández y Arauz Mercado (coords.), 2011, pp. 182-190.

SAntillán Esqueda, Martha, "La Descuartizadora de la Roma: aborto y maternidad. Ciudad de México, década de los cuarenta”, en Cárdenas y SPeckman (coords.), pp. 355-383.

SANTILlán Esqueda, Martha, "Mujeres y leyes posrevolucionarias. Un análisis de género en el Código Penal de 1931”, en Iter Criminis. Revista de Ciencias Penales, 13 (abr.-jun. 2016), pp. 125-171.

SANTIllán Esqueda, Martha "Posrevolución y participación política. Un ambiente conservador (1924-1953)”, en Maza Pesqueira (coord.), 2014, pp. 151-195. 
Santillán Esqueda, Martha, Delincuencia femenina. Ciudad de México, 1940-1954, México, Instituto Mora, Instituto Nacional de Ciencias Penales, 2017.

SMART, Carol, "La teoría feminista y el discurso jurídico", en Birgin (comp.), 2000, pp. 31-71.

Sosenski, Gregorio y Susana, Sosenski, "En defensa de los niños y las mujeres: un acercamiento a la vida de la psiquiatra Mathilde Rodríguez Cabo", en Salud Mental, 33: 1 (ene.-feb. 2010), pp. 1-10.

Sosenski, Susana, El trabajo infantil en la ciudad de México, 1920-1934, México, El Colegio de México, 2010.

Speckman Guerra, Elisa, "Las flores del mal. Mujeres criminales en el porfiriato”, en Historia Mexicana, xLVII: 1 (185) (jul.-sep. 1997), pp. 183-229.

Speckman Guerra, Elisa, "Morir en manos de una mujer: homicidas e infanticidas en el porfiriato", en CASTro y TERrazas (coords. y eds.), pp. 295-319.

Spota, Luis, Casi el paraíso, México, Era, 2008.

Torres Septién, Valentina, "Una familia de tantas. La celebración de las fiestas familiares católicas en México (1940-1960)”, en Gonzalbo Aizpuru (dir.), 2006, pp. 171-205.

TuÑón, Julia, Mujeres de luz y sombra en el cine mexicano. La construcción de una imagen 1939-1952, México, Instituto Mexicano de Cinematografía, El Colegio de México, 1998.

Urías Horcasitas, Beatriz, "Eugenesia e ideas sobre las razas en México, 1930-1950”, en Historia y Grafía, 17 (2001), pp. 171-205.

Urías Horcasitas, Beatriz, "Eugenesia y aborto en México (1920-1940)", en Debate Feminista, 27 (abr. 2003), pp. 305-323.

Urías Horcasitas, Beatriz, Historias secretas del racismo en México (19201950), México, Tusquets, 2007.

VIesCa, Carlos, "La Gota de Leche. De la mirada médica a la atención médicosocial en el México posrevolucionario", en Agostoni (coord.), 2008, pp. 195-217. 